\title{
To the Issue of Increasing the Efficiency of Operation of Energy Transmission Systems
}

\author{
Irine Berdzenishvili and Manana Siradze \\ Department of Chemical Technology and Biology, Georgian Technical University, Tbilisi 0175, Georgia
}

Received: May 13, 2016 / Accepted: May 27, 2016 / Published: August 31, 2016.

\begin{abstract}
This paper presents an overview of the safety performance of the major existing pipeline transmission system in Canada, USA and Europe. The article deals the experience of Georgia in the development of pipeline transport. The information on the distribution of catastrophic failures and incidents per individual cause is given. The role of corrosion in these failures is considered. To ensure efficient and reliable operations of oil and gas pipelines, the new compositions of competitive cost effective protective pipe enamel coatings have been developed.
\end{abstract}

Key words: Pipeline transmission systems, failure, corrosion, protective coatings, safety.

\section{Introduction}

Today the stability of socio-economic development in the world is largely determined by the decision of the problems of rational use of energy resources and ensure the safety of oil and gas piping systems to avoid and reduce the risk of accidents caused by corrosion. Corrosion is a phenomenon of deterioration of the pipelines [1-3].

U.S. Department of Transportation's PHMSA (Pipeline and Hazardous Materials Safety Administration) represents an overview of the safety performance of the major existing pipeline transmission system in the Canadian pipeline system and the U.S. system [3, 4]. As is shown in Fig. 1, corrosion accounts for about $50 \%$ of the significant failures in Canadian gas transmission systems-more than twice the proportion realized in the United States. Thus, the Canadian experience is somewhat different from the U.S.

In Europe the situation is different - corrosion has less effect on the failure frequency $[3,5]$. According to the 6th report of the EGIG (European Gas Pipeline

Corresponding author: Irine Berdzenishvili, Ph.D., professor, research fields: corrosion and functional coatings.
Incident Data Group), the major cause of incidents remains external interference (50\% of all incidents), followed by material (steel) defects (17\%) and corrosion (only 15\%). This distribution can be attributed to high population density, which has significantly increased the outside force failure rate.

The Caspian Sea is considered as one of the most important regions in the world for petroleum resources and a major supplier for oil and gas to European markets. The transport of these resources to the customers is carried out by pipelines through Georgia.

The SCP (South Caucasus pipeline), which is recognized as a high priority project for the European Union and a vital part of the Southern Corridor is among the projects by passing the territory of Georgia. The pipeline is now being expanded to accommodate additional gas from the second stage of the Shah Deniz (Shah Deniz Stage 2) development project. Shah Deniz-2 is one of the world's largest energy projects which will ultimately deliver gas to Europe [6]. This project is for energy security and diversification of energy and will never be successful without taking into consideration the effect of corrosion on the life span of the steel pipes. 


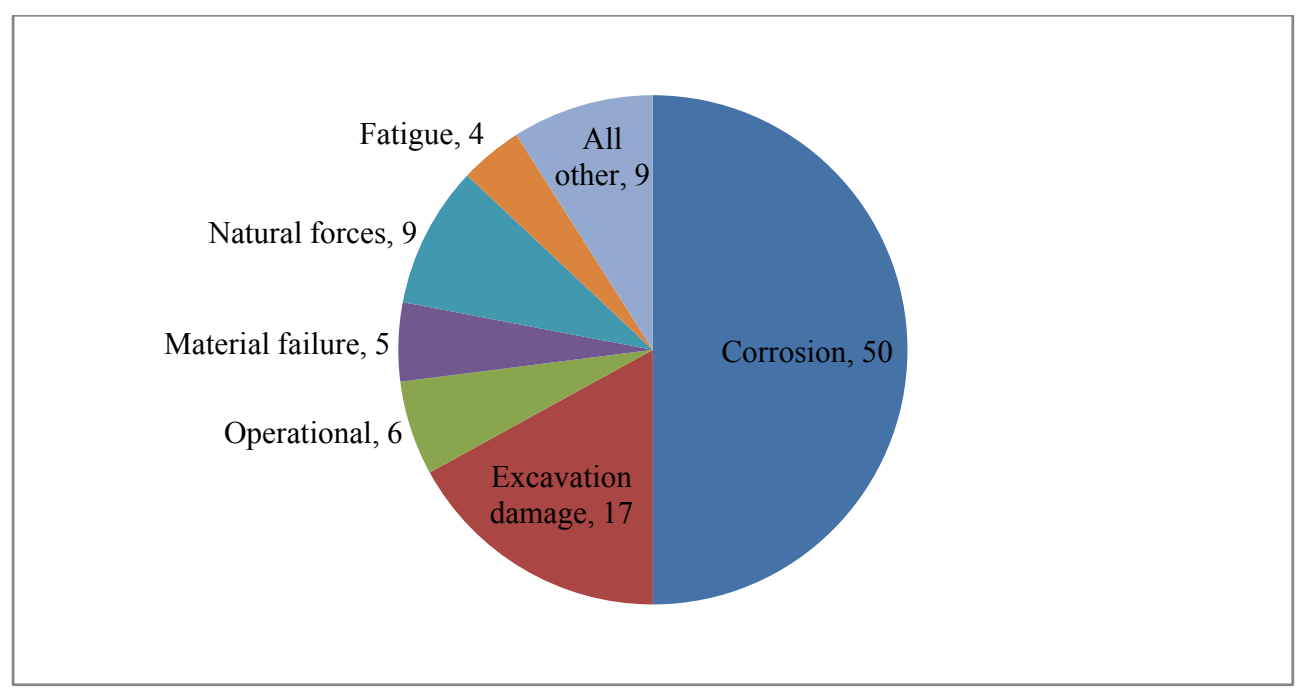

Fig. 1 Causes of the 46 ruptures that occurred in Canadian pipelines (1984-2004).

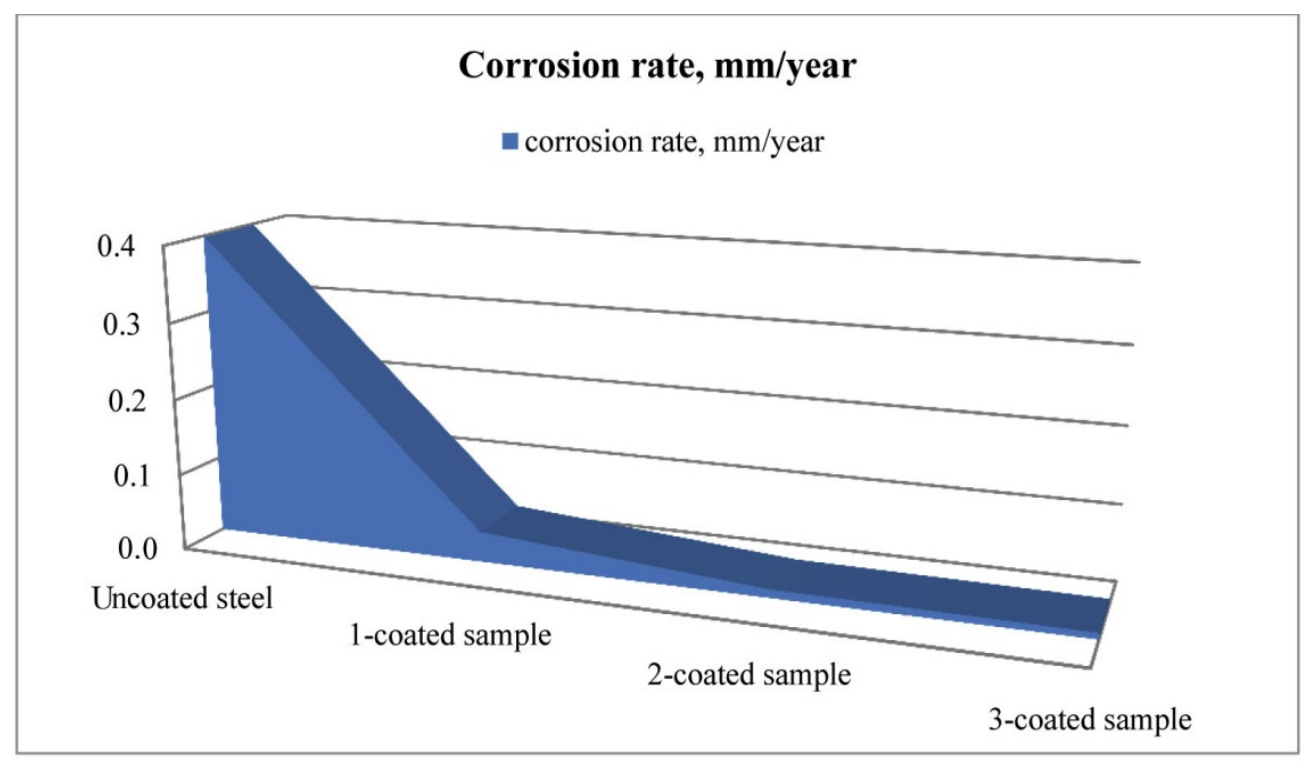

Fig. 2 Corrosion rate of experimental samples.

\section{Results and Discussion}

To solve the problem of corrosion we have developed the functional corrosion-resistant glass enamel coatings, which make it possible to protect oil and gas pipeline surfaces in extreme operating conditions [3,7]. To prepare coatings modern $1 \mathrm{C} / 1 \mathrm{~F}$ ( 1 coat $/ 1$ fire $)$ direct enameling technology was used. So advanced groundless technology proceeds in one stage and 2 times reduces energy, raw materials consumption and number of operations. Innovative enamel coatings have attracted much interest because they possess a unique combination of properties including high thermo-mechanical parameters, the absence of entrapped organic growth on the pipe inner surfaces and resistant to corrosion destruction and abrasion.

Corrosion monitoring techniques alone provide direct and online measurement of metal loss/corrosion rate in pipeline systems [8]. We undertook a laboratory research study with enamel-coated and uncoated work steel samples that completely immersed in the model NACE TM-0177 solution with the maximum percentage of hydrogen sulphide concentration expected in operations over a period of 90 days. Three 
different types of enamel coatings were investigated: No. 1-pure enamel, No. 2 and No. 3-composite enamel coatings. According to the calculations the obtained pipe coatings reduce steel corrosion rate in 3-4 orders of magnitude (Fig. 2).

After an exposure period the coating surface remained intact and the enameled specimens of $1 \mathrm{C} / 1 \mathrm{~F}$ exhibited the required stable adherence strength. Uniform corrosion was observed on the uncoated steel samples.

The advantages of main pipelines with smooth, glossy surfaces are the constancy of their hydrodynamic characteristics, flow rate and pump pressure desired for energy infrastructure projects. Thanks to the high electrical resistivity of obtained enamel coatings $\left(\rho_{293} \geq 10^{10} \Omega \cdot \mathrm{m}\right)$ such pipeline systems will be fully isolated from the induced current effects emitted by high-voltage power lines.

\section{Conclusion}

Overall results show that competitive law-melting composite enamels of dark color meet the requirements of ISO standards for enameled steel pipes and can effectively eliminate existing hidden dangers of the pipeline. Thus, it is apparent that proper preventive corrosion control strategies have a major impact on the safety, environmental preservation and the economics of pipeline operation.

\section{References}

[1] Cramer, S. D., and Bernard, S. 2006. ASM Handbook Volume 13C: Corrosion: Environments and Industries. Materials Park, OH: ASM International, 1026-36.

[2] Shubin, V. S., and Ryumin, Y. A. 2006. Reliability of Equipment of Chemical and Oil-Refining Industries. Moscow: Chemistry.

[3] Kamkamidze, K., Berdzenishvili, I. G., and Kamkamidze, E. 2014. Gas-Piping Systems, Risk Assessment and Assurance of Safety. Tbilisi: Technical University.

[4] National Energy Board. 2011. Focus on Safety and the Environment. A Comparative Analysis of Pipeline Performance, 2000-2009. https://www.neb-one.gc.ca/ sftnvrnmnt/sft/archive/sftprfrmncndctr/fcssft/2011/20002009 fcssft-eng.pdf.

[5] Gas Pipeline Incidents 1970-2004. 2005 6th EGIG Report: Doc.Number EGIG 05.R.0002.

[6] South Caucasus Pipeline (SCP), Georgia, Turkey, Azerbaijan. Accessed April 10, 2016. http://www.hydrocarbons-technology.com/projects/southcaucasus-pipeline-scp-georgia-turkey-azerbaijan/.

[7] Berdzenishvili, I. G. 2012. "Functional Corrosion-Resistant Enamel Coatings and Their Adherence Strength.” Acta Physica Polonica A. 121 (1): 178-80.

[8] Canadian Association of Petroleum Producers. Accessed March 15, 2016. http://www.capp.ca/. 